\title{
A METHODOLOGY FOR EVALUATING LARGE TRUCK ACCESS TO INTERMODAL AND OTHER FACILITIES
}

(KYSPR-98-189)

\section{Research Report KTC-98-14}

by

Lisa Aultman-Hall
KENTUCKY TRAMSPORTAION CENTER LDEARY

\author{
Michael L. Hill \\ and
Kenneth R. Agent
in cooperation with
Kentucky Transportation Cabinet
Commonwealth of Kentucky \\ and \\ Federal Highway Administration \\ U.S. Department of Transportation
}

\begin{abstract}
The contents of this report reflect the views of the authors, who are responsible for the facts and accuracy of the data presented herein. The contents do not necessarily reflect the official views or policies of the University of Kentucky, the Kentucky Transportation Cabinet, or the Federal Highway Administration. This report does not constitute a standard, specification, or regulation.
\end{abstract}

July 1998 


\section{TABLE OF CONTENTS}

Page

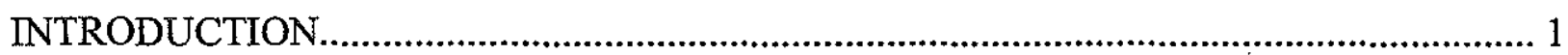



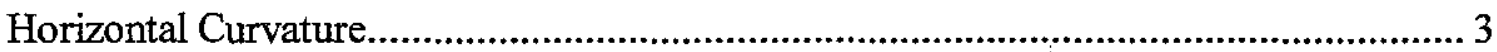

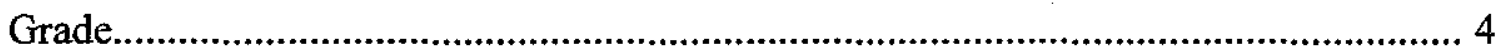

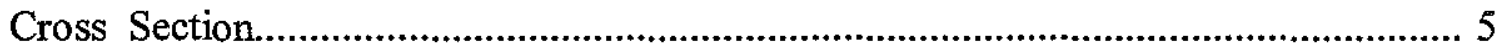

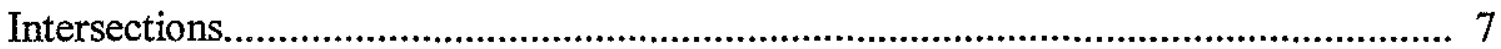

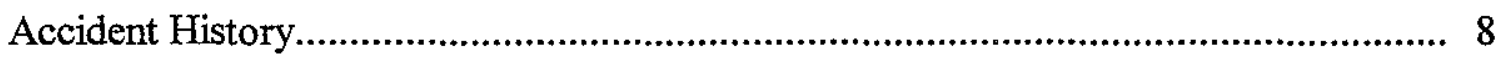

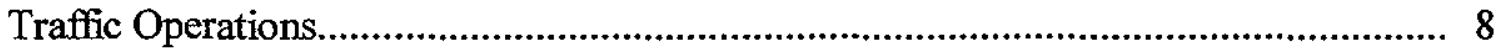

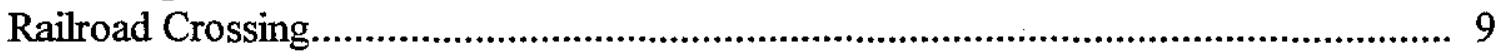

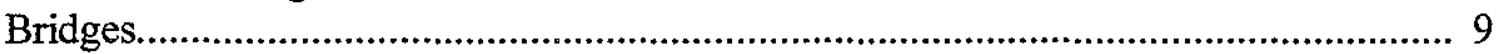

Subjective Roadway Features....................................................................... 10

Feature Evaluation Summary........................................................................... 10

TRANSFORMING ROUTE SECTION ADEQUACY INTO ROUTE EVALUATIONS........ 10

Problem Truck-Points and Problem Truck-Miles........................................................ 10

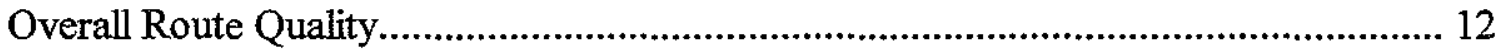

Maintenance Improvement Locations................................................................ 12

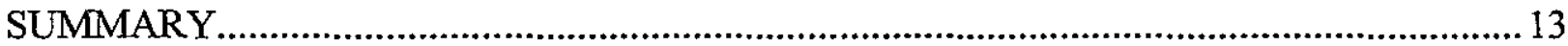

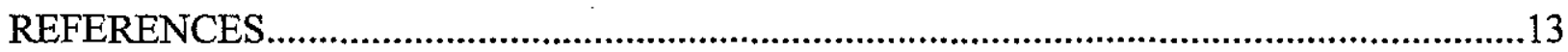




\section{TABLE SUMMARY}

Table 1: Summary of Route Feature Evaluation Techniques .................................................11

Table 2: Interpretation of the Overall Route Rating ...........................................................12 


\begin{abstract}
In a recent project for the Kentucky Transportation Cabinet (KYTC), researchers were tasked with developing a method to objectively evaluate the access for large trucks between intermodal or other truck traffic generating sites and the National Highway System (NHS). The routes evaluated were the actual roadway segments used by large volumes of trucks traveling between the intermodal or other facilities and the NHS. This choice to evaluate specific heavily used roadway segments, as opposed to evaluating an entire highway or roadway corridor was based on the recommendation of the state-wide Intermodal Advisory Panel which advised the Cabinet on intermodal issues. This allowed researchers to identify and focus on the actual problems being experienced by the truck traffic, even when the routes included segments of many different highways and jurisdictions. Part of this study included the development of objective measures that could be used for comparing and prioritizing problem sections. This paper documents the methodology that was developed and is currently being used to evaluate routes to 50 truck trip generators throughout Kentucky. The procedure begins with a telephone survey with site operators/managers to identify problems along the route. Each route is evaluated with respect to three types of features: subjective, point and continuous. The rankings of each point and continuous element into the categories of "preferred", "adequate", and "less than adequate" is converted to a relative urgency rating by assigning relative weights for truck volume and section length. Point and subjective features are identified for spot improvements where appropriate. Finally, the research team grades the overall route on a subjective scale of 1 to 10 .
\end{abstract}




\section{INTRODUCTION}

In a recent project for the Kentucky Transportation Cabinet (KYTC), researchers were tasked with developing a method to objectively evaluate the access for large trucks between intermodal or other truck generating sites and the National Highway System (NHS). The NHS in this case was assumed to be the main through routes for truck transport and its design appropriate for truck traffic. In Kentucky, there are 2,798 miles designated as NHS roadways, including 763 miles of interstates. However, the sites which trucks need to access are often off the NHS. This is particularly true of some intermodal facilities or natural resource operations, such as river ports and mining operations, which may be located at the end of the road system and not necessarily along main highway routes. In these cases and others, large numbers of trucks are using non-freeway state-maintained roads or even county routes, to travel from the NHS to their destination. Two geocoded state-wide databases were available which contained the location of truck-trip generators: intermodal terminals and other facilities with greater than 50 trucks per day accessing the site. These databases had both been collected in recent years as part of the Cabinet's intermodal planning process. Rather than evaluating an entire single highway or roadway corridor, the actual routes used between intermodal and other facilities (or clusters of facilitates) and the NHS were evaluated. This approach was recommended by the state Intermodal Advisory Panel which is sponsored by and provides direction to the KYTC on intermodal issues. In this way, the study could focus on the actual route segments in use and the actual problems being experienced by the truck traffic even when the route uses many different highway sections that fall under the responsibility of different jurisdictions. This type of approach is also applicable to economic development related access studies where the routes leading to prime development sites may cross several jurisdictions and include both state and local roads. Objective measures that allowed for prioritization of route problems were also needed. This paper documents the methodology that was developed and is currently being used to evaluate routes to 50 truck trip generator sites throughout Kentucky.

Intermodal and other truck generating sites were analyzed using a GIS program to determine which sites were located in clusters and to determine their distance from the NHS. Clusters of facilities were then chosen for study based on total trucks per day and distance to the NHS, while ensuring that a variety of modes, commodities and geographic areas throughout the state was included. Transportation planners from Highway Districts and Area Development District offices were asked to recommend sites with truck access problems.

Once a site or cluster of sites was identified for potential route evaluation, the managers of the facilities were contacted (by fax and subsequently by phone). The nature and purpose of the study was described to the managers to solicit their cooperation. Those interested in participating were then asked to provide details regarding truck traffic, to identify the routes used to travel to the National Highway System and to identify the location and time of day of traffic problems affecting their trucks. The largest typical truck using the route was obtained as if was used to calculate many of the geometric adequacy measures described below. Finally, information regarding the origin, destination, quantity, and mode of freight flowing through the facility were collected for use in other freight commodity flow modeling studies. A letter and local area map was faxed to individual companies or organizations two days 
prior to the telephone contact in order to discuss route usage. The cooperation of the site managers has been very good. All managers have requested a copy of the final report, which is offered in the initial phone contact.

The sites have, on average 1.5 routes, that trucks use to travel to the NHS. Routes average 2.5 miles in length with some as long as 25 miles. Before the site inspections and data collection were conducted, some data processing work was necessary. In order to relate the routes identified by the site managers to the information contained in the KYTC state-wide Highway Information System (HIS) database, the routes were digitized into a GIS database. The HIS data is stored by state road milepoint and can be related to the routes through the State's road GIS coverage. Once the routes were entered they were related to the HIS database information in order to download the following route segment data needed to calculate the evaluation indices: horizontal curvature, grade, milepoints, AADTs, percent trucks, lane widths, shoulder widths, shoulder types, number of lanes, and intersection control. Finally, the geocoded routes were used to print maps to ease field work and communicate findings. Once the preliminary information was known, routes were video taped in both directions. In some cases the video was made while following a truck to better illustrate the problems along the route, such as narrow lanes or insufficient turning radii.

The first and primary evaluation procedure involved labeling each individual section and/or point feature along the routes as "preferred", "adequate", or "less than adequate" according to the evaluation procedures developed. The following features were evaluated in this manner: curve offtracking, maximum safe speed on horizontal curves, grade, lane width, shoulders, railway crossings, sight distance, and bridge sufficiency. The data on these features was often contained in the state's Highway Information System (HIS) database housed in the KYTC Division of Transportation Planning. In cases where HIS data was not available, including all county maintained roads, site visits were conducted to collect the needed information. The choice of which access-related features to evaluate (described in detail in the next section) was influenced by the need to keep the data collection effort for each site within the limited resources available.

The overall urgency or absolute measure of adequacy with respect to each feature is related to not only the adequacy of individual features along the route sections but also the length of the sections and the number of trucks using them. A simple procedure is presented in the second to last second of this paper to convert the "preferred", "adequate" and "less than adequate" ratings for individual features into aggregate measures of problem truck points and problem truck miles that are summed over the entire route.

Several other features were evaluated although it was not possible or practical to consider labeling them into the three categories. These features included pavement condition, clear zone, accident history, traffic level of service, and other subjective features such as parking, pedestrian traffic, land use conflicts, and dust/noise issues. Another evaluation scheme was necessary in order to include these more subjective items as well as to counter the bias in the previous measure for long routes or routes with larger volumes of trucks. A scale of 1 through 10 was developed and applied to each overall route based on the judgement of a panel of transportation engineers on the research team. Finally, it was possible to compile a 
list of spot improvements along each route that might improve access and could be accomplished through routine maintenance.

\section{ROUTE FEATURE EVALUATIONS}

This section describes the geometric and operational aspects of the truck routes that are being evaluated using the "preferred", "adequate" or "less than adequate" grading. The method relies on data collected in the field, obtained from the HIS and other databases. The next section of the paper provides the methodology and for converting these individual segment or point measures into a more absolute rating to allow for comparison between routes or route segments.

The information presented here includes only features that the study team agreed fall within reasonable objectives and resources for a project of this scale. Other possible features (such as pavement markings and turning sight distance) were considered as well as other (usually more intensive) methods for evaluating the features discussed here.

\section{Horizontal Curvature}

There are two aspects of trucks traveling around horizontal curves that must be evaluated: offtracking and the maximum safe speed. Large trucks require a wider lane width on curves than on tangent portions to accommodate the tracking of the rear wheels outside of the path of the front wheels. This lateral difference can require wider lane widths on curves to prevent trucks from encroaching into adjacent (usually opposing) lanes or the shoulder. A Policy on Geometric Design of Highways and Streets (AASHTO, 1994) recommends that for many situations the curve sections be designed wider than the tangent sections based on the design vehicle, overall roadway width, radius of curve, and design speed. Many field techniques for evaluating offtracking required the collection of difficult quantities such as chord lengths and offset distances. The following offtracking formula (Millar and Walton, 1984) is used in this study due to its relative ease of use and the need to only have data on lane width, curve radius and typical axle spacings.

where

$$
\mathrm{MOT}=\mathrm{R}-\operatorname{sqrt}\left(\mathrm{R}^{2}-\mathrm{L}^{2}\right)
$$

$$
\begin{aligned}
& \text { MOT }=\text { maximum offtracking, } \\
& \text { sqrt }=\text { square root, } \\
& \mathrm{R} \quad=\text { turn radius, and } \\
& \mathrm{L}^{2} \quad=\text { sum of the squares of axle spacings of the truck under consideration }
\end{aligned}
$$

As an example, for a typical truck width of 8.5 feet (102 inches), there can be no more than 3.5 feet of offtracking before a truck is unable to negotiate a turn and remain within a standard 12 foot lane. A design vehicle having wheelbases of 20 and 46 feet for the tractor and trailer on a $300-\mathrm{ft}$. radius will experience $4.2 \mathrm{ft}$. of offtracking. The following guidelines were used to determine if each curve was rated as "preferred", "adequate", or "less than adequate". The "preferred" situation occurs when a truck with its front wheels in the center of the lane can negotiate the turn without offtracking. The "adequate" situation occurs when 
a truck can keep its back wheels within the lane while placing the front wheels at the outside edge of the travel lane. In the "less than adequate" case, the lane is narrower than the swept path of the vehicle and the truck cannot avoid encroaching on the opposing lane or shoulder.

PREFERRED: ADEQUATE: LESS THAN ADEQUATE:

\author{
MOT $<1 / 2$ (lane width - vehicle swept path) \\ MOT $<=$ lane width - vehicle swept path \\ MOT > lane width - vehicle swept path
}

The maximum safe speed on a curve is related to the speed a vehicle can travel around a horizontal curve before the centrifugal force causes the vehicle to skid off the road. This speed can be determined empirically given the superelevation rate, side friction and radius of the curve. Because superelevation and side friction can change over time due to resurfacing and weathering, the ball bank indicator is recommended for evaluating the maximum safe speed in this study. The centrifugal force angle is read directly from the indicator while driving the route. Typically the maximum comfortable curve speeds occur when ball bank readings are less than 12 degrees. For this study, a passenger car containing the ball bank indicator was driven along the routes. Where reduced speed advisory signs were posted before the curve, this reduced speed was evaluated, as opposed to the speed limit which was used along the other curves. The curve rating is then determined as follows.

PREFERRED: $\quad$ ball bank reading at speed limit not over 12

ADEQUATE: ball bank reading less than or equal to 12 at advisory speed

LESS THAN ADEQUATE: ball bank reading greater than 12 at curve advisory speed

\section{Grade}

Upgrades on highways can cause trucks to lose speed depending on the steepness, length of the slope, and the power-to-weight ratio of the vehicle. Large trucks slow significantly more on upgrades than passenger cars, causing inconsistencies in traffic speed. Studies have shown that vehicles that deviate from the average speed of traffic increase the likelihood for accidents (AASHTO, 1994). Slow moving trucks can also be a level of service issue in that they cause delay for other traffic. The grade sections to be evaluated can be selected while observing slow moving trucks in the field, reducing the amount of field work required.

A Policy on Geometric Design of Highways and Streets (AASHTO, 1994 ) provides speed reduction graphs for heavy trucks given percent and length of upgrade. The rating of "preferred", "adequate", or "less than adequate" is based on speed reduction. The AASHTO graphs are used with percent and length of grade information from the HIS database or measured in the field. Where possible, direct observation of the speed reduction of 4 to 6 trucks was undertaken to observe speed reduction. In the coal mining areas of Kentucky this was necessary for coal haul trucks since their weight to horsepower ratio is lower than the average truck assumed within the AASHTO guidelines. The recommended minimum speed reduction allowed in design is $15 \mathrm{~km} / \mathrm{h}$ (AASHTO, 1994). Recognizing that trucks on a downgrade may increase speed when approaching an upgrade, AASHTO suggests adjusting the allowable speed read from the graphs an additional $10-15 \mathrm{~km} / \mathrm{h}$ when a downgrade precedes the upgrade. In this situation, the permissible speed reduction (from the speed entering the grade) for large trucks becomes $25-30 \mathrm{~km} / \mathrm{h}$. 
Upgrades were considered "preferred" when separate climbing lanes are present but in other cases the following classifications were used to evaluate existing grade. The speeds shown in parentheses for upgrades preceded by a downgrade are only used when speed reductions are estimated from the AASHTO graphs. When observed speed reductions are used, the first speed is used regardless of whether the section is preceded by a downgrade.

PREFERRED:

up to $8 \mathrm{~km} / \mathrm{h}$ speed reduction $(18 \mathrm{~km} / \mathrm{hr}$ if preceded by downgrade)

ADEQUATE: $\quad$ a maximum of $15 \mathrm{~km} / \mathrm{h}$ speed reduction (up to $25 \mathrm{~km} / \mathrm{h}$ if preceded by downgrade)

LESS THAN ADEQUATE: greater than $15-\mathrm{km} / \mathrm{h}$ speed reduction $(25 \mathrm{~km} / \mathrm{h}$ when preceded by downgrade)

\section{Cross Section}

There are many roadway cross-section elements that might reasonably have an effect on truck access: pavement quality, lane width, shoulders, curbs, sidewalks, drainage channels, sideslopes, and traffic barriers. In this study lane width, clear zone, shoulders and surface pavement quality were chosen for evaluation due to their applicability to truck operations and the amount of data collection that would be required.

Lane width has one of the largest effects on driver safety and comfort of any roadway feature (AASHTO, 1994). Because trucks are significantly wider than passenger cars, the problems resulting from inadequate lane widths are increased for trucks. Lane width recommendations are provided by AASHTO for both rural and urban arterials, as well as collector roads. Typical lane widths are $3.0,3.3$, and 3.6 meters $(10,11,12 \mathrm{ft}$.$) . The 3.6$-meter lane is considered the most desirable width for all modern roadways, especially where trucks are present. The 3.3 meter lane is less desirable but has been used extensively and is considered acceptable on rural and urban arterials with low ADT and design speeds. However, 3.0 meter lane widths are insufficient where trucks are present (AASHTO, 1994). Lane widths are compiled in the HIS database for all state maintained roads. Those not available can be easily measured in the field. The criteria to be applied to lane widths in this study are as follows.
PREFERRED:
3.6-meter lanes ( 12 foot)
ADEQUATE:
3.3-meter lanes (11 foot)
LESS THAN ADEQUATE: 3.0 meters or less (10 foot)

The purpose of the clear zone is to allow errant vehicles an opportunity to safely recover and, therefore, it must be free of obstructions such as culvert headwalls, utility poles, and fences, as well as trees and other vegetation. Guidelines for the required clear zone distance can be found in the Roadside Design Guide (AASHTO, 1996). This required distance, measured laterally from the edge of the traveled way, is a function of speed and side slope.

The clear zone recommended by AASHTO for rural and urban locations with and without curbs could have been used for this evaluation. However, due to the labor required to collect 
side slope and distance to obstructions along entire route lengths, a more subjective approach was developed. The engineer evaluating the route is responsible for recording any obstructions within the recommended clear zone width as well as any locations where barriers such as guard rails may be needed. The distance to some obstructions within the recommended clear zone width that extend along route segments, such as fences, stone walls, drainage ditches, and utility poles, was estimated while driving. In some cases, a single object such as a large tree can be noted. The "preferred", "adequate" or "less than adequate" ratings can not be used for this feature.

A shoulder is the usable portion of a roadway adjacent to the travel lanes that can be used for emergencies (AASHTO, 1994). A usable shoulder can have a grade no steeper than 1:4 and may have a paved or stabilized gravel surface. If properly maintained, a turf surface shoulder may be considered acceptable. The shoulder will ideally be a minimum of three meters in width. Although shoulders of 1.8 to 2.4 meters $(6-8 \mathrm{ft}$.) are acceptable on minor highways the full three meters $(10 \mathrm{ft}$.) is recommended if such highways carry significant numbers of trucks (AASHTO, 1994). While shoulders narrower than three meters allow stopped motorists to get partially out of the traveled way, and are better than no shoulder, a stopped truck may still present a significant hazard to passing motorists and therefore are not wide enough for effective emergency use. Therefore, in this study three meters of any surfaced shoulder was considered acceptable on all roads under study as truck routes. It should also be noted that, in addition to the lateral clearance required for trucks to completely exit the travel lane, a vertical clearance of 13.5 feet is required for the shoulder to be used by a typical truck. This lateral clearance on shoulders is noted only if problematic. The shoulder widths for state maintained roads in Kentucky are available in the HIS database. The following rating categories apply to shoulders in non-urban areas.

PREFERRED: $\quad$ a minimum of 3 meters of paved shoulder ADEQUATE: $\quad$ a minimum of 3 meters of unpaved shoulder LESS THAN ADEQUATE: less than 3 meters of usable shoulder

Pavement condition affects the operation of large trucks because it affects braking distance and, in severe cases, the ability of the driver to maintain control of the vehicle. The condition of the pavement changes over time depending on the volume and composition of traffic on the roadway. Information relating to the structural adequacy of the roadway is currently not available statewide, and an attempt to measure this was outside the scope of this project. The current truck weight classification of the route sections was reported for reference. The KYTC maintains the inventory of pavement rideability ratings for all state-maintained roads. This rating is a scale of 0 to 4 indicating the relative surface roughness of the pavement $(0=$ impassible; $4=$ excellent). Other research at the Kentucky Transportation Center presents a method to estimate the general condition of pavements (Allen 1990) given the rideability index and average daily traffic, and this could be used to translate into "preferred", "adequate" and "less than adequate" ratings. However, in an attempt to reduce the amount of detailed work for each route and to maintain the scope of the project, this feature was evaluated subjectively during the site visits. 


\section{Intersections}

Sight distance (SD) and turning radii were two geometric characteristics of intersections considered relevant for truck routes and were therefore evaluated within this study.

There should be sufficient sight distance at intersections to allow vehicles approaching an intersection to stop when necessary. There should also be sufficient sight distance at an intersection to allow vehicles at a stop or yield controlled approach to safely turn or travel across the roadway. This crossing/turning sight distance is only indirectly considered through evaluation of the stopping sight distance. The stopping sight distance is a function of the vehicle's braking ability, driver characteristics, the nature of the object or stimuli, and driver expectancy. AASHTO (1994) provides minimum sight distances for passenger cars, and recommends that these be used for heavy trucks as well. Although large trucks require longer braking distances, the increased SD due to driver eye height is assumed to compensate for this, and passenger car sight distances are used as the design standard (Transportation Research Board, 1986). The stopping sight distance (SSD) required will be as recommended by AASHTO (1994) and is based on design speed and friction on wet pavements. The locations where SD might be insufficient are identified by observation by experienced researchers and then measurements are taken to quantify the distance. The following conditions are used to convert the findings into the three category scale.

PREFERRED: $\quad \mathrm{SD}>=\mathrm{SSD}$

ADEQUATE: $\quad \mathrm{SD}<\mathrm{SSD}$, but warning sign is present to indicate stop, signal, or intersection ahead

LESS THAN ADEQUATE: SD < SSD

Agent and Pigman (1997a) have developed templates for the various design vehicles to be used as a supplement to the templates developed by AASHTO to determine appropriate turning radii. All right turns required for the trucks along the route were evaluated, but only those left turns that appeared to have insufficient turning radii or are identified as less than adequate during facility interviews are evaluated. Rights turns are a concern because if the rear wheels track outside of the lane lines when turning, the wheels may hit the curb at the edge of the lane or track onto the shoulder, potentially hitting objects (fire hydrants, signs) or pedestrians that are near the intersection. Alternatively, in order to stay on the road, the truck might have to encroach on opposing lanes either on the road the truck turns from, or the road the truck turns onto. This situation is undesirable.

Right turning radii at intersections are approximated by use of a measuring wheel. The point of intersection of the projection of the straight edge lines of each road into the intersection is estimated. Next, the distance from that point of intersection back to the point where the curve begins is measured separately for each leg of the intersection. In most cases, the radius is assumed to be an average of these two measurements. The lane widths are obtained from the HIS database or through additional field measurements. A comparison is made between the required turning radius and the radius estimated in the field. At most intersections the investigator also observes several trucks negotiate the turn and subjectively rates the adequacy of the turning radius. If the road being turned onto has more than one lane 
in the desired direction, it was considered appropriate if the truck turns into either lane on the street even when there is only one right turning lane on the originating road. That is, vehicles need not turn into the curb lane, but encroaching on an opposing traffic lane would result in a "less than adequate" rating. Often damage to utility poles, curbs or turf beyond the curb or edge of pavement can indicate whether trucks have difficulty managing the turn. The categories to be applied to each right and left turn evaluated are as follows.

PREFERRED: $\quad$ truck turning from right lane can complete maneuver without leaving the travel lanes

ADEQUATE: $\quad$ truck may partially encroach on other lanes (on either the first or second road) in the same direction but does not encroach on opposing traffic

LESS THAN ADEQUATE: truck enters opposing traffic lane or must start from a position completely outside the right most lane

\section{Accident History}

The accident history along the truck routes is also of interest in this study. Agent and Pigman (1997b) use a critical accident rate methodology in preparing Kentucky's Annual Highway Safety Plan. This procedure compares state-wide average critical accident rates previously calculated for a given highway type to the accident rate on a given roadway segment. In the KTC studies, roadway segments having truck accident rates greater than the statewide $99^{\text {th }}$ percentile (for a particular highway type) are identified as high accident locations which warrant further investigation. This compilation of high truck accident sections was reviewed to determine if any sections along the individual routes were listed. This fact is reported but cannot be labeled as "preferred", "adequate", or "less than adequate".

The numbers of total accidents and truck accidents was also tallied along the route. The location and frequency of accidents in a three year time period are mapped along the route, and any single spot or segment with a large concentration of accidents are identified. The percent of truck accidents is also considered and compared to the percent of truck traffic along the route.

\section{Traffic Operations}

The amount of traffic that can be accommodated along routes is of concern for all vehicles, including trucks, as it relates to factors such as speed, travel time and freedom to maneuver. A basic and widely accepted method of categorizing quality of operation at intersections and along basic roadway segments is level-of-service (LOS) as described in the Highway Capacity Manual (HCM) (Transportation Research Board 1994). For this study, there is potentially a large number of intersections and sections along each route. Due to the large data collection effort and length of time that would be required to evaluate every intersection, only those that present a problem for trucks using the route were evaluated. These "problem" intersections and sections were identified during the initial phone survey of the facility. The times and days of concern were also noted and the intersection LOS was evaluated at these times. 
There are four types of data that are required to evaluate intersection LOS: the geometric configuration (lane diagram); the type of traffic control and traffic signal timing plan (if signalized); 15-minute volume counts; and the saturation flowrate. These items were easily collected in the field. The LOS can then be determined using HCM software with the following ratings can be applied.

PREFERRED: LOS A or B

ADEQUATE: $\quad$ LOS $\mathrm{C}$ or $\mathrm{D}$

LESS THAN ADEQUATE: LOS E or F

Intersections generally govern the LOS of roadways where intersections are not more than two miles apart. For those cases where intersections do not control the LOS, the HCM procedures for evaluating basic segment LOS can be used. This might be the case along extended upgrades. However, within urban areas, the surveys have revealed a number of travel time concerns along a complete arterial corridor. In these cases, travel time observations are taken through the corridor and the HCM procedure based on route type and road character is used to determine level of service. The "preferred", "adequate", and "less than adequate" ratings were applied as described above.

\section{Railroad Crossings}

The (KYTC) maintains a database containing all of the approximately 2600 railroad crossings on public roadways in Kentucky. USDOT accident prediction formulae are used with this information to rank all of the 2,600 crossings from most severe to least severe. However, in this study it is more important to consider the appropriateness of particular crossings for trucks rather than overall accident hazard. A "preferred" highway rail crossing would 1) be close to 90 degrees, 2) have sufficient sight distance (if there is insufficient sight distance warning gates and/or signals should be present), 3) have good pavement/surface quality and 4) have nearly level approach grades. Steep approaches require longer for trucks to accelerate and cross the tracks from a stop. This increased time to clear the tracks requires longer sight distances at unsignalized crossings to ensure tracks can be cleared safely.

Crossings with steep approach grades or humped crossings cause longer wheelbased trucks to "bottom out" and possibly become stuck halfway across the tracks. A crossing was considered "adequate" if it exhibited only three of these four characteristics. "Less than adequate" crossings exhibited only had two or less desirable qualities.

\section{Bridges}

The KYTC Division of Operations currently maintains an inventory of all bridges in the state as required by FHWA. This database contains detailed geometric and operational information for each bridge along with a composite sufficiency rating (scale 1 to 100). This composite rating was a weighted score of three categories: structural adequacy and safety; serviceability and functional obsolescence; and essentiality for public use. The sufficiency rating is used to allocate federal money toward replacing or rehabilitating bridges according to this measure. The sufficiency rating and the prioritizing levels used by KYTC for this purpose is used in this study as follows. 
PREFERRED:

ADEQUATE:

LESS THAN ADEQUATE: Sufficiency Rating
Sufficiency Rating $80.0-100$

Sufficiency Rating $50.0-79.9$

$0-49.9$

\section{Subjective Roadway Features}

The roadway features included in this evaluation of truck access represent a wide range of issues. However, this list is not comprehensive and subjective features must be discussed in these studies. There are many other factors affecting the suitability of roadways for trucks that cannot be reasonably measured. These issues might include adjacent land use and parking as related to safety, noise, or air pollution. Parking maneuvers along the roadway can also reduce roadway capacity. In many cases, traffic control devices are important along truck routes. The appropriateness of the signs, signals and warning signs is also noted within this category.

\section{Feature Evaluation Summary}

The roadway feature rating procedures described are intended to be the guide for evaluating individual road section features for suitability for truck access. The roadway features identified in this chapter represent those that are most related to truck access, and can be reasonably evaluated. The input of the Research Advisory Committee was sought to determine which particular features and detailed evaluation methods are of highest priority for this project and should therefore be pursued. Table 1 summarizes the consensus reached for the features described in this section.

\section{TRANSFORMING ROUTE SECTION ADEQUACY INTO ROUTE EVALUATIONS}

The features discussed in the previous section fall into three categories, as indicated in the last column of Table 1: subjective, point, and continuous. A method is needed to assign an adequacy value and calculate the sum of these along routes in order to compare the relative urgency of needed improvements. It was assumed that the urgency or severity of a deficient section or point is directly related to the volume of trucks using the section. That is, of two equally deficient sections the one carrying more trucks is considered a more serious need for improvement. In the case of sections, (as opposed to points) the length of the section is also an issue. All other things being equal, the section carrying more truck-miles is in more urgent need of improvement. This section of the paper describes the three route evaluation products that will result from this project. The first of these products is aimed at normalizing the "preferred", "adequate" and "less than adequate" ratings to incorporate truck volume and section length summed along whole routes.

\section{Problem Truck-Points and Problem Truck-Miles}

For point elements, the measures recorded using the methods in the previous section are normalized by truck volume per day. This absolute measure of urgency or need is equal to the number of truck problem points per day summed over the route for each feature individually. If a point on a route has been labeled "preferred", it will not contribute to the 
Table 1: Summary of Route Feature Evaluation Techniques

\begin{tabular}{|c|c|c|c|}
\hline Feature & Methodology & Team Consensus & Feature Type \\
\hline Offtracking & $\begin{array}{l}\text { Lane Width with formula } \\
\text { based on wheel and axle } \\
\text { spacing }\end{array}$ & $\begin{array}{l}\text { Evaluate where observation of trucks indicates } \\
\text { offtracking - use HIS data and collect in field }\end{array}$ & Point \\
\hline $\begin{array}{l}\text { Max. Safe Speed on } \\
\text { a Curve }\end{array}$ & $\begin{array}{l}\text { Ball Bank Indicator } \\
\text { Reading }\end{array}$ & $\begin{array}{l}\text { Evaluate complete route due to ease of data } \\
\text { collection }\end{array}$ & Point \\
\hline Grade & $\begin{array}{l}\text { Speed Reduction Tables } \\
\text { with Percent Grade and } \\
\text { Direct Observation }\end{array}$ & $\begin{array}{l}\text { Evaluate where observation of trucks indicates } \\
\text { speed reduction occurs using HIS data and } \\
\text { collect in field as needed }\end{array}$ & Continuous \\
\hline Lane Width & $\begin{array}{l}\text { HIS data and field } \\
\text { measurement }\end{array}$ & $\begin{array}{l}\text { Review complete route due to ease of data } \\
\text { collection }\end{array}$ & Continuous \\
\hline Clear Zone & Observation & Subjective evaluation & Subjective \\
\hline Shoulders & $\begin{array}{l}\text { HIS data - field } \\
\text { measurement }\end{array}$ & $\begin{array}{l}\text { Evaluate where HIS data is available and } \\
\text { estimate based on observation elsewhere }\end{array}$ & Continuous \\
\hline Pavement Condition & KTC Rating Method & Subjective evaluation & Subjective \\
\hline $\begin{array}{l}\text { Stopping Sight } \\
\text { Distance }\end{array}$ & field measurements & $\begin{array}{l}\text { Measure only when observation indicates } \\
\text { possible problem }\end{array}$ & Point \\
\hline Turning Radii & $\begin{array}{l}\text { Field measurements and } \\
\text { observation of trucks }\end{array}$ & $\begin{array}{l}\text { Measure only when observation indicates } \\
\text { possible problem }\end{array}$ & Point \\
\hline Accident History & Accident data files & $\begin{array}{l}\text { Look at truck accident totals on route and } \\
\text { check KTC high truck accident sites }\end{array}$ & Subjective \\
\hline Intersection LOS & traffic counts & $\begin{array}{l}\text { Only where problems are indicated by } \\
\text { managers/ truckers }\end{array}$ & Point \\
\hline Route LOS & $\begin{array}{l}\text { traffic counts and travel } \\
\text { time studies }\end{array}$ & $\begin{array}{l}\text { Only where problems are indicated by } \\
\text { managers/truckers }\end{array}$ & Continuous \\
\hline RR Crossings & Based on field inspection & Evaluate all crossings & Point \\
\hline Bridges & KYTC Sufficiency Rating & Evaluate all bridges & Point \\
\hline
\end{tabular}

cumulative total of problem truck points per day. The other two categories, "adequate" and "less than adequate", will increase the cumulative total. If a point has been labeled "adequate", every truck that travels by that route point (not just those trucks traveling to/from the site under study) will count as one truck problem point per day. It was assumed that a "less than adequate" point counts for twice the weight of an "adequate" point, meaning each "less than adequate" point along the route contributes two truck problem points per day for every truck that travels past that point. Some point features, such as bridges, require use of the bi-directional truck volume, while others, such as turning radii, use only the truck volume in the direction affected. In this way, for every point attribute category shown in Table 1, a cumulative number of truck problem points per day per route is reported. Whole routes can then be compared for urgency or relative need of attention. However, this absolute measuring system also has the advantage of being applicable to single points within one route or between different routes.

When continuous features are evaluated, the length of section must also be considered. In other words, it was assumed that if the same number of trucks traveled down two lengths of 
otherwise identical roadway having insufficient lane width, the longer section would be considered the more urgent section. Therefore, the measure for absolute urgency of continuous features will be the weighted truck miles along problem sections. Again the weight of a "less than adequate" section versus an "adequate" section will count as two. Travel along "preferred" feature sections will not contribute to the total.

\section{Overall Route Quality}

Through use of the problem trucks per day and problem truck miles per day, specific sections or routes can be compared on a feature by feature basis to determine the urgency of needed improvements. However, there is also a need for a measure of the overall route quality, considering all route features, including those subjectively evaluated. Some consideration was given to weighting each of the features such that a composite quantitative measure could be determined. It was concluded that such a measure would be inaccurate due to the relative weighting of different features and the inability to include subjective features or elements such as traffic operations which are evaluated at only selected points. Therefore, the decision was made that the researcher who inspected the route, together with the research team, consider the data collected and then grade the overall route on a scale of 1 through 10 . In this case, 10 would represent a route that currently accommodates trucks with reasonably good standards of geometry, safety and operating conditions and therefore needs no improvements. The guidelines for this rating are shown in Table 2 .

\section{Table 2: Interpretation of the Overall Route Rating}

\begin{tabular}{|l|l|}
\hline $\begin{array}{l}\text { Overall } \\
\text { Route } \\
\text { Rating }\end{array}$ & Qualitative Interpretation of Rating \\
\hline 1 & Trucks should not be using this route \\
\hline 2 & Major construction is required to improve this route \\
\hline $3-5$ & Minor improvements are required on this route \\
\hline $6-8$ & Minor improvements could improve this route \\
\hline 9 & Minor problems exist that do not seriously impede truck access \\
\hline 10 & Trucks are served with reasonable access \\
\hline
\end{tabular}

\section{Maintenance Improvement Locations}

The final type of result that is provided for each site or cluster of sites is a list of maintenance improvement locations along the routes. These locations might result from subjective or point features that have been evaluated. The maintenance improvements list includes locations where a feature might be improved simply by routine work or maintenance already performed by some agency. Such routine work can sometimes only be conducted when it is drawn to the attention of appropriate agencies (either KYTC district offices or in some cases the county or municipality). As an example of a problem that could be rectified with a maintenance improvement is an intersection sight distance problem that can be improved by simply removing overgrown vegetation or trees along the roadway. 


\section{SUMMARY}

There has been a need identified by those within the freight transportation industry that serve on Kentucky's Intermodal Advisory Panel to evaluate the routes between intermodal facilities and the National Highway System. In order to pursue this goal, as well as consider other routes leading to large truck trip generators within the state, a procedure has been developed to evaluate route features and their appropriateness for truck traffic. The procedure involved a telephone survey with site operators/managers to allow the problem areas to be identified. Each route is evaluated with respect to three groups of features: subjective, point, and continuous. The rankings of each point and continuous element into the categories of "preferred", "adequate" and "less than adequate" is then converted to a relative urgency rating by assigning a relative weight according to truck volume and section length. Point and subjective features are identified for maintenance improvements where appropriate. Finally, the research team grades the overall route on a subjective scale 1 to 10 .

This process is currently being undertaken for 50 sites within Kentucky. Facility managers have been helpful in supplying information related to truck routes, problem locations and types of trucks using the routes. The procedure has required an average of only two days per site to complete the field work. The process has been found to be a good balance that takes advantage of existing state databases, minimizes labor intensive data collection, and focuses on features most relevant to truck access problems.

\section{ACKNOWLEDGEMENTS}

The authors would like to thank Carl Dixon and others at the Kentucky Transportation Cabinet as well as the Study Advisory Committee for valued assistance on this project. The funding of the Cabinet is gratefully acknowledged; however, the conclusions and recommendations made here are those of the authors and not necessarily the Kentucky Transportation Cabinet.

\section{REFERENCES}

Agent, K.R., and Pigman, J.G., Development of Turning Templates for Various Design Vehicles, Report No. KTC-97-2, Kentucky Transportation Center, Lexington, KY, 1997 a.

Agent, K.R., and Pigman, J.G., Analysis of Traffic Accident Data in Kentucky (1992 - 1996), Report No. KTC-97-18, Kentucky Transportation Center, Lexington, KY, 1997b.

Allen, D.L., Review and Analysis of Pavement Management Practices in Kentucky, Report No. KTC-90-4, Kentucky Transportation Center, Lexington, KY, March 1990.

AASHTO (1994) A Policy on Geometric Design of Highways and Streets, 1994, AASHTO, Washington, D.C. 
Millar, D.S., and Walton, C.M., "Offtracking of the Larger, Longer Combination

Commercial Vehicles", University of Texas at Austin, Presentation at the $64^{\text {th }}$ Annual TRB Meeting, January 1984.

Transportation Research Board (1986) Twin Trailer Trucks, Special Report 211, National Research Council : Washington D.C.

Transportation Research Board (1994). Highway Capacity Manual Special Report 209, Third Edition; Transportation Research Board, National Research Council, Washington, D.C., 1994. 